
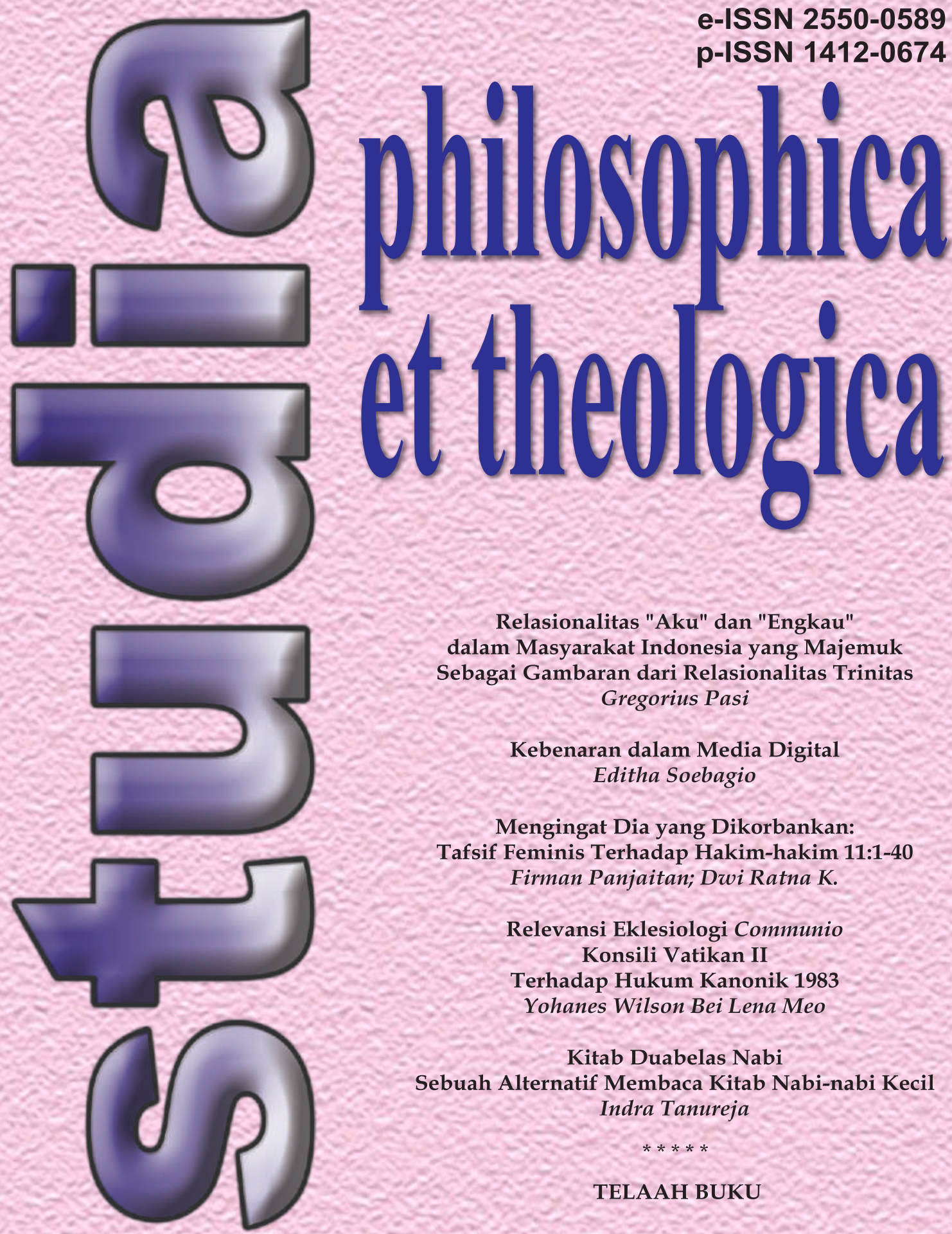

Relasionalitas "Aku" dan "Engkau" dalam Masyarakat Indonesia yang Majemuk Sebagai Gambaran dari Relasionalitas Trinitas Gregorius Pasi

Kebenaran dalam Media Digital Editha Soebagio

Mengingat Dia yang Dikorbankan:

Tafsif Feminis Terhadap Hakim-hakim 11:1-40

Firman Panjaitan; Dwi Ratna K.

Relevansi Eklesiologi Communio Konsili Vatikan II

Terhadap Hukum Kanonik 1983

Yohanes Wilson Bei Lena Meo

Kitab Duabelas Nabi

Sebuah Alternatif Membaca Kitab Nabi-nabi Kecil Indra Tanureja

$* * * * *$

TELAAH BUKU

Sekolah Tinggi Filsafat Teologi

Vol. 20 No. 2, Oktober 2020

Widya Sasana, Malang 


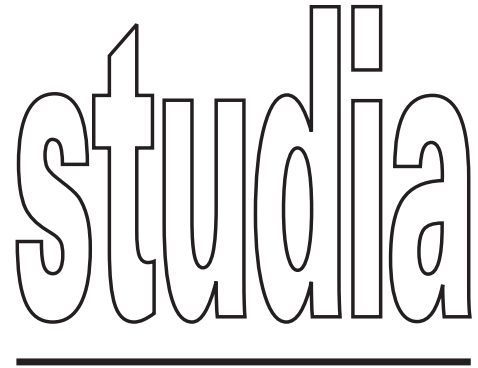

STUDIA PHILOSOPHICA ET THEOLOGICA (ISSN Print 1412-0674 and ISSN Online 2550-0589) is a bilingual (Indonesian and English language) and peer reviewed journal published by Center of Research of Widya Sasana School of Philosophy Theology, Malang. STUDIA specializes in researched papers related to contextualization and inculturation of theology and philosophy from inter-disciplinary-methodological point of view. Journal has 2 issues per year (April and October).

STUDIA welcomes philosophical and theological contributions from scholars with various background of disciplines. This journal uses English and Indonesian Language. STUDIA is an open access journal whose papers published is freely downloaded.

\section{FOCUS AND SCOPE:}

STUDIA focuses on philosophical and theological studies based on both literary and field researches. The emphasis of study is on systematic attempt of exploring seeds of Indonesian philosophy as well as contextualization and inculturationof theology in socio-political-historical atmosphere of Indonesia.

Scope of STUDIA covers various perspectives of philosophical and theological studies from interdisciplinary methodology and cultural-religious point of view of traditions.

\section{PUBLISHER :}

P3M Sekolah Tinggi Filsafat Teologi

Widya Sasana Malang

J1. Terusan Rajabasa 2,

Malang 65146 Indonesia

Telp. 0341 - 552120

Fax. 0341 - 566676

Email : stftws@gmail.com

Website : ejournal.stftws.ac.id
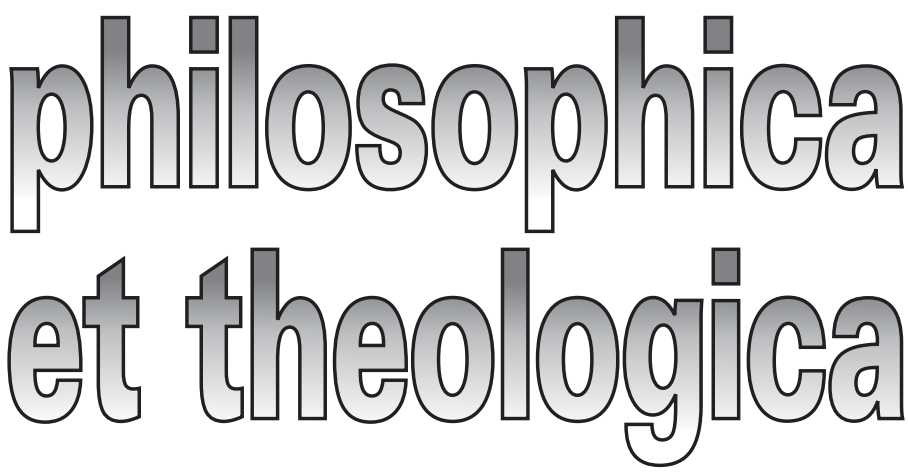

e-ISSN 2550-0589
p-ISSN 1412-0674

\section{Editor in Chief}

FX. Eko Armada Riyanto (Google Scholar; h-index: 5); Widya Sasana College of Philosophy Theology, Malang.

\section{Managing Editors}

Edison RL. Tinambunan (Google Scholar; h-index: 1); Widya Sasana College of Philosophy Theology, Malang.

Kurniawan Dwi Madyo Utomo (Google Scholar); Widya Sasana College of Philosophy Theology, Malang.

\section{Editorial Board}

Pius Pandor (Google Scholar; h-index: 2); Widya Sasana College of Philosophy Theology, Malang.

Valentinus Saeng (Google Scholar; h-index: 2); Widya Sasana College of Philosophy Theology, Malang.

Yohanes I Wayan Marianta (Google Scholar); Widya Sasana College of Philosophy Theology, Malang.

Raymundus Made Sudhiarsa (Google Scholar; h-index: 2); Widya Sasana College of Philosophy Theology, Malang.

Alphonsus Catur Raharso (Google Scholar; h-index: 2); Widya Sasana College of Philosophy Theology, Malang.

Petrus Maria Handoko (Google Scholar; h-index: 2); Widya Sasana College of Philosophy Theology, Malang.

Antonius Denny Firmanto (Google Scholar; h-index: 2); Widya Sasana College of Philosophy Theology, Malang.

Carl Sterkens (Scopus ID: ... ; Google Scholar; h-index: 7); Katholic Radboud University, Nijmegen, Niederlands.

Daniel Franklin Pilario(Google Scholar; h-index: 4); Adamson University, Manila, Philippines.

Roland Tuazon (Google Scholar; h-index: 2); Adamson University, Manila, Philippines.

Emanuel P.D. Martasudjita (Scopus ID: 6026801; Google Scholar; h-index: 4); Sanata Dharma University, Yogyakarta.

Johanis Ohoitimur (Google Scholar; h-index: 3); Pineleng College, Manado.

Antonius Eddy Kristiyanto (Google Scholar; h-index: 5); Driyarkara College, Jakarta.

Mudjia Rahardja (Scopus ID: ... Google Scholar; h-index: 10); Maulana MalikIbrahim Islamic State University, Malang.

Justinus Sudarminta (Google Scholar; h-index: 7); Driyarkara College, Jakarta.

\section{English Language Advisor}

Maria Lichmann (North Carolina)

Odilia Rahayu Widji Astuti

Indonesian Language Advisor

Didik Bagiyowinadi

\section{Information and Technology}

Imilda Retno Arum Sari

\section{Publication Frequency}

Studia Philosophicaet Theologica is published two times a year (April and October) 


\section{Studia Philosophica et Theologica}

\section{Author Guidelines}

1. Article must have150-word abstract in both English and Indonesian language and four or five keywords.

2. Article should be between 5000 and 8000 words, inclusive of references and footnotes.

3. Article must be a study based on either literary (text) or field research.

4. Article will be submitted in Word (single-spaced and 12-point font) for consideration by email attachment, beside online submission as required. Authors must log in before submit their article.

5. Headings:

- First-level headings (e.g. Introduction, Conclusion) should be in bold, with an initial capital letter for any proper nouns.

- Second-level headings should be in bold italics, with an initial capital letter for any proper nouns.

- Third-level headings should be in italics, with an initial capital letter for any proper nouns.

6. Notes and Bibliographies please click https://www.dropbox.com/s/y2nb9l3cvb9 fg47/Notes\%20and\%20Bibliography\%20Turabian\%20Style.pdf? $d l=0$.

7. Article submitted will be peer-reviewed by qualified academics; this process may take weeks or months. All submitted papers are subject to review of the editors, editorial board, and reviewers.

8. Author should be willing to respond to questions from readers of their articles; and in case there is correction, author must refine the article as soon as possible.

\section{Guidelines for Book Reviews}

1. Please include, at the beginning: Author, Title, Place, Publisher, Date, number of pages, ISBN of the book reviewed.

E.g., Taylor, Charles. A Secular Age. Cambridge: The Belknap Press of Harvard University Press, 2007. 874+x pp. ISBN-13: 978-0-674-02676-6.

2. The review begin with abstract, three or four keywords and continue with a brief overall description of the book.

3. The review may include:

- The content and its complexity of the book.

- Comments on the author's style and contribution of the book.

- Philosophical or theological methodology of presentation.

- Position of the philosophical or theological arguments in its field.

4. The preferred format for submissions is MS-Word.

5. Review should be about 1500 words long. The name, affiliation and email address of the reviewer should appear at the end of the review. 


\section{Studia Philosophica et Theologica E-ISSN 2550 - 0589 \\ ISSN 1412-0674}

Vol. 20 No. 2 Oktober 2020

Hal. 103 - 204

\section{DAFTAR ISI}

\section{ARTIKEL}

Relasionalitas "Aku" dan "Engkau"

dalam Masyarakat Indonesia yang Majemuk

Sebagai Gambaran dari Relasionalitas Trinitas

Gregorius Pasi..... $103-126$

Kebenaran dalam Media Digital

Editha Soebagio $127-141$

Mengingat Dia yang Dikorbankan:

Tafsir Feminis Terhadap Hakim-hakim 11:1-40

Firman Panjaitan; Dwi Ratna K. $142-159$

Relevansi Eklesiologi Communio Konsili Vatikan II

Terhadap Hukum Kanonik 1983

Yohanes Wilson Bei Lena Meo. $160-176$

Kitab Duabelas Nabi

Sebuah Alternatif Membaca Kitab Nabi-nabi Kecil

Indra Tanureja $177-196$

\section{TELAAH BUKU}

Theology of Culture

Nikasius Jatmiko $197-202$

Index $203-204$ 


\title{
KEBENARAN DALAM MEDIA DIGITAL
}

\author{
Editha Soebagio \\ Mahasiswi Program Doktoral STF Driyarkara \\ Email:edithasoebagio@gmail.com
}

\begin{abstract}
In just a decade, the truth that actually becomes a pillar in a life together turned out to be a lot of coloured false hood and lies. The practice of manipulating the truth is rife because humans are in thepost-truth era, an era where people are busy hiding the truth without making them feel dishonest. This situationis supported by the emergence of digital media which produces a lot of lies without going through the verification process. The claim of truth has been displaced by 'believability' and the institutionalization of lies is deliberately carried out to manipulate the truth. As a result, the real newsis a lie accepted as truth. And conversely the news that actually needs to be accepted as truth is considered a lie. This certainly brings harm to the people who should have the right to receive true news. False hood and lies still exist in our communication media although Covid-19 pandemic renders individuals and society extremelyvulner able in all respect, whilstweallrely more than ever on computer system, mobile devices and the internet. This situation reminds us, that media literacy needs to be done so that people are responsible for promoting and spreading the right news based on the virtue of honesty. It requires hard work and commitment, not just embrace the right for every one to speak, but also to he arand listen, to discern which is the truth as best we can, not just for our present, but it will be very valuable for our future.
\end{abstract}

Keywords: truth, post-truth, digital media, society, Covid-19, vulnerability

\begin{abstract}
Abstrak
Dalam periode yang singkat, kebenaran yang sejatinya menjadi pilar dalam kehidupan bersama ternyata banyak diwarnai kepalsuan dan kebohongan. Praktek manipulasi kebenaran marak dilakukan dalam eraposttruth, sebuah masa di mana orang ramai menyembunyikan kebenaran tanpa membuatnya merasa tidak jujur. Situasi ini didukung oleh munculnya media digital yang banyak memproduksi berita bohong tanpa melalui proses verifikasi. Kebenaran digantikan dengan kesesuaian dengan opini pribadi dan instusionalisasi kebohongan dengan sengaja dilakukan untuk memanipulasi kebenaran. Akibatnya berita yang sebenarnya merupakan kebohongan diterima sebagai kebenaran, dan sebaliknya berita yang sebenarnya perlu diterima sebagai kebenaran dianggap sebagai kebohongan. Hal ini tentu membawa kerugian bagi masyarakat yang seharusnya memiliki hak untuk
\end{abstract}


menerima berita yang benar.Kepalsuan dan kebohongan masih tetap mewarnai media kita dalam situasi pandemic Covid-19, di saat individu dan masyarakat dengan segala kerentanannya menggantungkan diri pada sistem komputer, peralatan komunikasi digital dan internet.Situasi ini mengingatkan kita, bahwaliterasi media perlu dilakukan agar orang bertanggung jawab mempromosikan dan menyebarkan beritayang benar berlandaskan keutamaan kejujuran. Hal ini membutuhkan kerja keras dan komitmen, bukan hanya mengupayakan agar setiap orang dapat menyampaikan pendapatnya, tetapi juga untuk mendengarkan dan memahami, serta berusaha sebaik mungkin untuk mengupayakan kebenaran, bukan hanya untuk saat ini saja, tetapi akan sangat berharga untuk masa depan kita.

Kata-katakunci: Kebenaran, post-truth, media digital, masyarakat, Covid-19, kerentanan

Kebenaran merupakan ilusi-ilusi yang sudah kita lupakan bahwa itu adalah ilusi-ilusi. Mereka adalah metafora yang sudah lusuh dan terkuras oleh kekuatan pengindraan. Koin yang kehilangan relief dan sekarang sudah menjadi logam dan bukan lagi koin. ${ }^{1}$ Friedrich Nietzsche (1844-1900)

\section{Pendahuluan}

Millenium kita ditandai dengan asumsi yang menyatakan bahwa ada banyak hal lain yang dianggap lebih penting dari kebenaran dan kejujuran. Friedrich Nietzsche mempertanyakan keyakinan kita,"apakah kita menginginkan kebenaran, dan mengapa kita tidak lebih memilih kebohongan?" 2 . Selain menuduh bahwa 'kebenaran merupakan prasangka dari para filsuf' dan tidak lebih dari fiksi yang menguntungkan penguasa, Nietzsche gencar mengkritik konsep pemikiran modern dan pencerahan.Selain pernyataannya yang terkenal tentang "Godisdead", Nietzche juga terkenal dengan klaimnya tentang "revaluasi semua nilai" (revaluationofallvalues) yang menyatakan bahwa "yang disebut kebaikan bagi manusia modern bukanlah keutamaan, yang disebut sebagai agama bukanlah religiositas, dan yang disebut kebenaran bukanlah ketulusan". ${ }^{3}$ Pendapat Nietzsche inimelemahkan motivasi untuk

1 Friedrich Nietzsche, Philosophy and Truth: Selection from Nietzche Notebook of Early 1870, Editor dan terjemahan Daniel Breazeale (New Jersey: Humanity Press), 84.

2 Friedrich Nietzsche, Beyond Good and Evil, dalam Trueto Life (New York:Vintage, 1966), 83.

3 Philip SmithA and Alexander Riley, Cultural Theory an Introduction (Oxford: Blackwell Publishing, 2009), 19, pernyataan dikutip dari karya Walter Kaufmann, Nietzsche: Philosopher, Psychologist, Antichrist yang diterbitkan tahun 1950. 
memperjuangkan kebenaran, karena mengubah tatanan nilai yang berlaku dalam masyarakat modern. Ajarannya ini menjadikan Nietzsche sebagai Nabi Postmodernisme ${ }^{4}$, yang menginspirasi lahirnya gejala sosiologis post-truth. Etika post-truth memperkenankan orang menyembunyikan kebenaran tanpa membuatnya merasa tidak jujur, meskipun orang memberlakukan standar ganda yang paradoksal, "kebohonganku dapat dipahami, tetapi kebohonganmu merupakan perbuatan keji".

Kehadiran media digital dengan spesifikasi yang konvergen ${ }^{5}$ dan cair menjadi lahan subur untuk perkembangan post-truth. Masyarakat dibanjiri dengan opini publik yang dipengaruhi emosi dan keyakinan pribadi, informasi yang sesat dan penyimpangan fakta dengan mudah meresap ketika hal itu sesuai dengan perasaan dan pemikiran kita, sementara kebenaran objektif faktual menjadi terpinggirkan. Berita yang tidak benar (hoax) dan berita palsu (fakenews) mengemas kebohongan, fitnah, dusta dan menjadi sangat cepat tersebar dengan memanfaatkan buzzer (pendengung) dari tokoh-tokoh masyarakat, artis atau orang-orang yang memiliki pemikiran dan keyakinan yang sepaham. Polarisasi masyarakat ini didukung oleh sistem algoritma bubble filter. Sistem logika ini memanjakan pengguna media digital dengan menyajikan informasi yang sesuai denganpenggunanya.Sistem juga mengisolasikan pengguna dari hal-hal yang tidak diminatinya. Media digital secara selektif menyajikan informasi yang sudah dipilah. Informasidisajikan mengacu pada penggunanya, seperti lokasi keberadaannya, situs yang sering dikunjungi ataupun data pencaharian (penggunaan mesin pencari/search engine), serta memisahkannya dari informasi yang bertentangan dengan minat penggunanya.

Tanpa sikap kritis dan kewaspadaan orang akan berada dalam ruang gema (echo chamber) dengan keyakinan bahwa apa yang didengarnya berulang dari masyarakat yang sepaham dengannya sebagai fakta dan kebenaran. Meskipun jika dibuktikan secara objektif asumsi mereka salah, mereka tetap pada keyakinannya. Akibatnya, kehidupan masyarakat terancam mengalami distorsi relasi. Orang dapat kehilangan kemampuan objektifnya untuk menilai,

4 Prof. Dr. J. Sudarminta, SJ. Setia Pada Kebenaran: Sumbangan Filsafat sebagai Ilmu Kritis, Pidato Pengukuhan Guru Besar Ilmu Filsafat (Jakarta: STF Driyarkara, 2007), 31.

5 Konvergen dapat dipahami dalam konteks teknologi dan lintas platform. Dalam konteks teknologi, konvergensi terbentuk karena melalui internet kita dapat memperoleh beragam bentuk media yang sebelumnya terpisah (artikel majalah, program radio, lagu, program televisi, video atau games) dalam kesatuan platform online yang dapat di-akses melalui laptop, tablet ataupun smartphone. Sedangkan konvergensi dalam arti lintas platform merupakan model bisnis yang melibatkan berbagai media dengan tujuan memberi pilihan kepada konsumen untuk memilih media yang sesuai. Meskipun kondisi ini tidak dengan sendirinya menghentikan format media yang telah kita kenal seperti surat kabar dalam dicetak. (Stephen J.A. Ward, Ethics and the Media (New York: Cambridge UniversityPress, 2011), 11-12. 
karena selalu mendapatkan informasi yang tidak berimbang tentang realitas. Kondisi ini diperburuk oleh kenyataan bahwa media digital tidak jarang digunakan juga untuk mendiskreditkan orang atau pihak tertentu ${ }^{6}$ dengan mengangkat topik-topik sensitif seperti agama, gender, etnis, serta sikap-sikap bermusuhan terhadap kelompok-kelompok yang tidak sepaham, sehingga mengancam toleransi dan keberagaman dalam masyarakat.

Dalam situasi real kehadiran bertubuh, orang memiliki kecenderungan berbohong ketika harga dirinya terancam ${ }^{7}$ atau berupaya menciptakan kesan yang baik kepada orang asing, ${ }^{8}$ tetapi orang akan lebih jujur terhadap orangorang terdekatnya. Kebohongan bukan hanya menjadi kemungkinan tindakan yang dapat dilakukan, melainkan menjadi hal yang dikehendaki. ${ }^{9}$ Orang dengan sadar memilih kebohongan dan bukan kejujuran dengan berbagai pertimbangan praktis. Sementara media digital sebagai realitas virtual dengan alternatif modalitas ${ }^{10}$ dan konteks, menciptakan relasi termediasi. Komunikasi tanpa kontak langsung (facetoface), tetapi melalui gadget atau komputer, memberi peluang untuk bereksperimen dengan ide, kreativitas bahkan identitas pribadi. Relasi termediasi melalui media digital mereduksi tubuh, raut muka, tatapan, nafas, nadasuara,gestur dan bahasa tubuh yang membangkitkan empati dan tanggung jawab dan mengubahnya menjadi keter'asing'-an.

Kebutuhan orang mendapatkan kesan (impression) yang baik dan penerimaan mempunyai wadah dalam media digital. Orang tidak terbeban lagi dengan keharusan menjadi jujur, lemah lembut dan santun, seperti ketika kehadirannya terikat dengan tubuh fisik.Identitas pribadiseperti ekspresi wajah, bahasa, gender, status dan elemen-elemen lain yang melekat pada kebertubuhannyayangrelatif tidak mengalami perubahan dari waktu ke waktu tidak nampak dalam media digital.Relasi tanpa perjumpaan fisik dalam media digital memberi peluang kepada penggunanya untuk mengkonstruksikan identitas mereka. ${ }^{11}$ Orang dapat menggunakan identitas yang sama dalam kehidupan realnya, mengubah sebagian dari identitas yang dimilikinya untuk mendukung interaksi sosialnya atau menciptakan identitas yang sama sekali berbeda dengan menjadi sosok yang diimpikannya. Meskipun

6 Pesan Bapa Suci Paus Fransiscus untuk Hari Komunikasi Sedunia Ke-53, diunduh 7 Mei, 2019.www.mirifica.net/2019/02/15/pesan-paus-untuk-hari-komunikasi-sedunia-ke-53.

7 Ralph Keyes, The PostTruth Era: Dishonesty and Deception in Contemporary Life (New York: St Moritz Press, 2004), 11.

8 Ibid, 16.

9 Ibid, 14.

10 Meminjam penjabaran substansi dari Immanuel Kant tentang definisimodalitas yaitu: mungkin/mustahil, ada/tiada, niscaya/kebetulan

11 Sherry Turkle, Alone Together: Why We Expect More from Technology and Lessfrom Each Other (New York: Basic Book, 2011), 183-184. 
demikian membiarkan hidup terus-menerus dalam kebohongan mengakibatkan orang terancam bahaya mengidap penyakit kepribadian ${ }^{12}$ serta menghapus peluang membangun relasi yang baik dan tulus dengan sesama.

Data penelitian secara statistik menunjukkan bahwa masyarakat kontemporer yang terhubungdengan internet melalui gadgetnyamemiliki tingkat kebohongan yang terbesar. Data initidak pernah terjadi pada masa sebelumnya. ${ }^{13}$ Kebohongan atau ketidakjujuran mengalami pertumbuhan secara eksponensial ${ }^{14}$ seiring dengan bertambahnya pengguna internet dan media sosial. Akibat dari pertumbuhan ini kebohongan menjadi epidemi yang mengancam kehidupanmasyarakat dan juga mengancam kehidupan pribadi. Masyarakat mengalami keresahan karena informasi-infomasi tentang penyakit, wabah, bencana, teror, kriminalitas, dll. yang tidak dapat dipertanggungjawabkan. Kebohongan dapatmengurangi wibawa pemerintah, selain itu masyarakat dapat kehilangan orientasinya terhadap keutamaan kebenaran dan kebaikan dalam kehidupan sosial. Kebohongan dalam kehidupan pribadi dapat mengakibatkan hilangnya kepekaanuntuk membedakan kebohongan dan kebenaran, menjadi lebih toleran terhadap ketidakjujuran, bahkan menjadi imun dan tidak merasakan lagi perbedaannya. Pengalaman bersama kita berhadapan dengan pandemi Covid19 yang memaksa kita mengubah sosialitas fisik kita menjadi ketergantungan terhadap media digital menghadapkan kita pada relasi problematis antara kemanusiaan, kematian dan teknologi. Teknologi seakan menjadi bagian dari takdir dari manusia modern yang berusaha mempertahankan aktivitasnya secara optimal dalam kondisi pembatasan sosialitas fisik.

\section{Kebenaran dalam Media Digital yang Rentan}

Media digital dapat menjadi sumber daya dan pengetahuan yang terbuka luas untuk dieksplorasi dan dimanfaatkan untuk pengembangan kreativitas dan potensi penggunanya. Melalui media digital setiap orang dapat mengekspresikan diri dengan memilih peran yang disukainya, sebagai reporter, komentator politik, kritikus budaya atau produser media. ${ }^{15}$ Peran-peran ini dapat dilakoninya dengan tanpa tuntutan persyaratan atau kredibilitas tertentu. Semua orang dapat mengemukakan opini dan keyakinan subjektifnya, meski tanpa mengandung kebenaran faktual-objektif. Kondisi ini menafikan objektivitas,mengancam keberagaman dan menjadi media bertumbuhnya spiral kebencian. Melalui internet dan media sosial kita dapat

12 Sudarminta, Setia Pada Kebenaran: Sumbangan Filsafat sebagai Ilmu Kritis, 23.

13 Keyes, op. cit, 28.

14 Pertumbuhan secara eksponensial menunjukkan peningkatan dengan laju perubahan yang mengalami percepatan seiring dengan waktu.

15 Carrie James, dkk. Young People, Ethicsand New Digital Media: A Synthesis from the Good Play Project (Cambridge dan London: The MIT Press, 2009), 1. 
menjalin relasi yang luas. Kita dapat berkomunikasi secara virtual dengan siapapun dan dimanapun untuk mendiskusikan berbagai permasalahan dengan berbagai status legalitas, keanehan dan pelanggaran hak.

Tanpa adanya hirarki dan organisasi vertikal, semua pihak secara bebas dapat terlibat dalam media digital. Secara substansial media digital menampung peretas (hacker), pelaku kejahatan digital, penggerak subkultur berdasarkan seksual dan gender(LGBT - lesbian, gay, biseksual dan transgender), jaringan terorisme, dll. Semua yang tertarik dapat mengambil bagian untuk terlibat dalam pengembangan internet (worldwide web) dan membangun forum komunikasi (web forum) untuk mensosialisasikan programprogram mereka, serta membagikan tautan(link) ataupun content yang lain, sehingga komunitas-komunitas ini juga mengisi ruang-ruang online ${ }^{16}$ Melalui media digital e-retailers, perbankan online (e-banking) dapat dengan mudah menjajakan program-program mereka, demikian juga kelompok subkultur dan jaringan terorisme dapat melakukan perekrutan anggota dan menjalankan kegiatan serta aksinya yang bertentangan dengan norma dan hukum yang berlaku. Mereka bertumbuh bersama pengguna media digital lain, terutama generasimilennialyang kehidupan kesehariannya tidak dapat lepas dari gadget.Generasi milennial merupakan fenomena masyarakat yang memiliki kehidupan hibrid yang menyatukan dunia real dan virtual. Pemerintah dapat campur tangan untuk kasus-kasus tertentu secara terbatas, jika dibandingkan derasnya perkembangan arus informasi yang interaktif.

Ruang komunikasi interaktif dalam media digital melibatkan penggunanya pada relasi transaksional, karenadapat saling memberi tanggapan kepada pengguna lain. Tanggapan, baik secara positif ataupun negatif, akan mendongkrak popularitas dan memberikan peluang untuk mendapatkan posisi dalam mesin pencari (searchengine) yang berkontribusi pada peningkatan traffic, serta meningkatkan elektabilitas pada masa kampanye. Follower dan likemerupakan sesuatu yang berharga, baik bagi individu-individu maupun pelaku bisnis dan media, ${ }^{17}$ karena berarti akan mendapatkan privilese akses untuk menjangkau masyarakat lebih luas. Selain menunjang sosialisasi konten melalui media digital, tanggapan yang diperoleh juga membuka peluang finansial. Kondisi ini dimungkinkan karena orang cenderung memilih tautan teratas dari mesin pencari. Mekanisme ini mendorong pengguna media digital untuk menampilkan dan mengemas content-nya secara menarik dan impresif.Mereka dapat memanipulasi foto atau informasi dengan tujuan menyembunyikan kebenaran yang tidak populer. Disukai adalah sesuatu yang tidak bisa diperkirakan, tetapi dapat dimanipulasi. Mereka yang memahami

16 Cameron, dkk. Deception in the Digital Aging: Exploiting and Defending Human Target Through Computer Mediated Communication (London: Academic Press, 2017), 126.

17 David Sumpter, Out numbered: From Facebook and Google Fake News and Filter Bubbles - That Algorithms that Control Our Lives (London, Bloomberg Sigma: 2018), 111. 
cara kerja mesin pencari dapat mendesain, agar suatu tautan memperoleh posisi tertinggi (rating) dalam mesin pencari.

Proses kerja media digital dilakukan melalui mekanisme mengubah realitas objektif dan kreasi simbolik seperti surat, garis, bentuk, catatan, lagu, harapan, tangisan, cerita, dan legenda menjadi sesuatu yang seragam dan 'bukan apa-apa'. ${ }^{18}$ Media digital mengolah kode-kode 1 atau 0 , on atau offmenjadisoftware yang terbuka. Media digital mengubah sesuatu yang tangible (nyata dan berwujud) menjadi virtual (intangible/tanpa wujud real). Melalui logika biner berbagai bentuk informasi dapat dibaca, di-duplikasi dan diteruskan. Komputer dan peralatan digital lain yang digunakan dapat menghasilkan sesuatu yang akurat, cepat dan menyerupai aslinya. Seperti foto yang merupakan paduan kristal/garam di atas serat kertas yang bisa dipegang dalam media digital diubah menjadi file dalam format JPEG ${ }^{19}$ yang merupakan suatu formula yang tidak bisa disentuh. Media digital mengubah momen yang dibekukan menjadi 'cair', mengakibatkan tempat ajaib seperti kamar gelap (darkroom) ${ }^{20}$ kehilangan kesakralannya. Fotografi saat ini lebih merupakan rumusan untuk menyusun titik-titik menyerupai sesuatu. Semua data dan gambar dalam bentuk digital merupakan objek yang siap untuk dimodifikasi, diteruskan dan disebarkan. Esensi kebenaran dalam fotografi di masa lampau dan kredibilitas fotografer hilang, sehingga kita harus sering bertanya, "Apakah ini real?"

Penipuan melalui media digital dapat dilakukan dengan efektif dan efisien dengan skala yang tidak pernah diperkirakan dalam sejarah. ${ }^{21}$ Menipu merupakan tindakan memberi pengarahan yang salah (misdirection), membentuk persepsi dan keyakinan dari resipien. Peningkatan konektivitas internet, peralatan digital dan software untuk editing menjadi unsur-unsur pendukung untuk menciptakan realitas baru yang semakin nyata, sehingga semakin menarik dan sulit dibedakan dengan realitas aslinya. Hal ini sangat rentan karena mengundang rasa penasaran yang menjadi perangkap untuk sosialisasi kelompok atau gerakan yang bertentangan dengan kebenaran

18 Foreword - James D. Kelly, Tom Wheeler, Photo truth or Photo fiction?: Ethics and Media Imaginery in the Digital Age (New Jersey: Lawrence Erlbaum Associates Publishers 2002).

19 JPEG merupakan format untuk memampatkan file gambar, singkatan dari Joint Photographic Experts Group.

20 Teknik fotografi konvensional, di awal abad ke- 19 menggunakan kamar gelap (darkroom), yaitu ruangan yang dikondisikan gelap sama sekaliuntuk memproses film dan kertas foto yang peka terhadap cahaya.Mengingat sebagian besar kertas foto hitam-putih peka terhadap warna biru, atau biru dan hijau, maka untuk membantu proses pengerjaannya dapat digunakan cahaya samar yang aman, yaitu warna merah atau kekuningan (amber) yang tidak langsung mengenai kertas foto.

21 Cameron, Deception in the Digital Aging: Exploiting and Defending Human Target Through Computer Mediated Communication, xx. (Bagian dari Introduksi: Cyber antropology and Deception). 
objektif faktual dan hukum. Banyak situs digunakan untuk perekrutan dan kegiatan pendanaan untuk kegiatan terorisme. Mereka mengundang targetnya melalui situs resmi yang menyediakan tautan pada cryptoweb yang dikhususkan bagi kelompok mereka dan tidak dapat diakses oleh masyarakat umum. Representasi situs mereka tersedia di banyak negara, sehingga pada saat mengalami permasalahan hukum, situs yang lain siap menggantikannya, sehingga dapat pulih dengan cepat. ${ }^{22}$

Masa depan media digital masih akan berkembang seiring daya pikir manusia, demikian juga kreativitas dan metode penipuan, antara lain melalui: para pengguna sosial media palsu yang diciptakan secara individual ataupun untuk tujuan tertentu, komunitas online yang melayani kepentingan tertentu, community fraud yang merupakan komunitas tersembunyi dapat dikelola oleh robot otomatis dan tanpa melibatkan manusia, jaringan saraf tiruan dan kecerdasan buatan (artificial intelligence) yang dapat difungsikan sebagai influencer untuk politik, sosial, keuangan atau kegunaan filosofis. Program dan perlengkapan yang canggih dengan karakter ini dalam jumlah besar merupakan tantangan potensial yang mengarahkan komunikasi dan tindakan masyarakat untuk mewujudkan rencana dan kepentingan pihak-pihak tertentu.

Teknologi modern melalui media digital menjadi ancaman yang mengeliminasi dimensi transendental manusia pada kehidupan sehari-hari yang banal. Menurut Heidegger, kondisi ini berarti manusia kehilangan autentisitasnya sebagai Dasein yang dari dirinya sendiri memang berbeda dengan yang lain. ${ }^{23}$ Dasein yang terlalu tenggelam dalam keseharian yang menjadi bagian dari masyarakat umum sebagai das Manakan kehilangan kemampuan kritisnya sebagai makhluk yang dapat berpikir dan menentukan dirinya di dunia, termasuk menentukan sikapnya terhadap kebenaran dan menjalin relasi yang bebas dengan teknologi ${ }^{24}$.

\section{Pudarnya Kebenaran dalam Era Post-Truth}

Kebenaran dalam pemahaman klasik Thomisme dimaknai sebagai korespondensi antara realitas dengan yang dipikirkan(ad equatioreiet intellectus) atau dalam keseharian kebenaran dipahami sebagai kesesuaian antara apa yang kita pikirkan, percayai dan nyatakan (baik secara lisan maupun tertulis) dengan kenyataan atau apa yang sesungguhnya terjadi. ${ }^{25}$ Sementara konsep

22 Keyes, The Post Truth Era: Dishonesty and Deception in Contemporary Life, 200.

23 Martin Heidegger, Being and Time, terjemahan Joan Stambaugh (New York: State University of New York, 1996), 10.

24 Martin Heidegger. The Question Concerning Technology and Other Essays, terjemahan William Lovitt (London: Garland Publishing, 1977), 26.

25 Sudarminta, Setia Pada Kebenaran: Sumbangan Filsafat sebagai Ilmu Kritis, 7. 
kebenaran dalam era post-truth merupakan antitesis dari konsep kebenaran yangbersifat ketunggalan (monolit), objektif dan universal. Skeptisisme dan relativisme mempengaruhi budaya post-truth dan menjadikan kebenaran memiliki nuansa monokrom dengan variasi kadar abu-abu, sehingga kebenaran bukan lagi konsep biner (hitam/putih) yang dapat ditentukan benar dan salahnya dengan jelas.Dalam era post-truth ini nilai kebenaran dan kejujuran cenderung rendah, karena kemapanan konsep kebenaran klasik yang memiliki sifat ketunggalan, objektivitas dan universalitasnya digugat dan dipertanyakan oleh para pemikir postmodern, selain itu sifat normatif kebenaran juga dibawa dalam berbagai aspek kehidupan manusia.

Kebenaran dalam era post-truth bukan lagi objektif dan normatif, melainkan terikat dalam konteks, sehingga bersifat dinamis dan berubah-ubah. Didukung kreativitas linguistik, berbagai istilah digunakan untuk merasionalisasi dan mengkonstruksikan kebenaran, seperti kebenaran imajinatif, realitas alternatif, kebenaran virtual, mendekati kebenaran, penyingkapan selektif, realitas bertambah (augmented reality), dll. Akibatnya kita semakin tidak sensitif terhadap sesuatu yang tidak wajar.Kebohongan ${ }^{26}$ dikemas menjadi sesuatu yang manis, menjadi kebenaran yang baru, salah ucap, dll. Eufemisme menjadi kekuatan bahasa yang luar biasa,hasil kreativitasyang mempengaruhi pola pikir masyarakat secara mendalam, karena menyembunyikan realitas kebenaran.

Meskipun survei di Amerika dan dimanapun,menunjukkan bahwa kebenaran diakui sebagai keutamaan yang bernilai, tetapi komitmen terhadap kebenaran berjalan seiring dengan praktek ketidakjujuran, ${ }^{27}$ karena tuntutan sosial dan kehidupan professional. ${ }^{28}$ Pertemanan dalam media digital, film dan televisi, surat kabar dan majalah mengemas kebohongan dan menjadikannya sebagai topik yang populer. Kebenaran dan kebohongan tidak memiliki perbedaan yang jelas lagi, sehingga orang menjadi lebih jujur di lingkungan privat dan intim, sebaliknya menjadi kurang jujur di lingkungan yang lain, tetapi orang akan sangat berhati-hati menyebut orang lain 'pembohong', karena sangat fatal dan akan menutup kemungkinan dialog selanjutnya. Orang cenderung memilih merasionalisasi kebenaran, karena masyarakat juga tidak menjatuhkan sanksi atas ketidakjujuran yang dilakukannya. Padahal tanpa kebenaran dan ketulusan relasi dalam media digital menjadi ruang isolasi. Orang menghabiskan sebagian besar waktunya di depan layar dengan kondisi terpuruk dalam kesepian dan kesendirian. Media digital memungkinkan orang menjalin relasi yang luas, tetapi tanpa kepercayaan dan sikap curiga relasi yang terbentuk memiliki ikatan yang

26 Keyes, The Post Truth Era: Dishonesty and Deception in Contemporary Life, 37-41.

27 Ibid, 18.

28 Ibid, 22. 
lemah. Relasi berlangsung tanpa keintiman, serta kehilangan semangat memberi dan menerima dengan tulus.

Pergeseran relasi fisik menjadi digital merupakan perubahan monumental dalam penyebaran informasi dan berbagai konten lain secara lebih cepat, akurat, persisten, mudah ditiru dan mudah dicaridalam cakupan yang luas, termasuk hoax dan fakenewos. Media digital merupakan hasil dari teknologi digital yang sekaligus merupakan teknologi intelektual yang mengubah cara pikir dan juga hal yang kita pikirkan. ${ }^{29}$ Pemikiran menjadi terserak akibat ledakan informasi, sehingga perhatian kita pada hal-hal penting bagi kehidupan kita, sekaligus juga terbagi pada hal-hal yang sebenarnya tidak kita butuhkan, tetapi menyita perhatian kita. Banyaknya waktu yang kita habiskan untuk mengakses media digital menyebabkan kita terjebak dan kehilangan peluang untuk menjalin relasi fisik yang kaya.

Pemikiran kita cenderung menjadi dangkal, karena perubahan dan kecepatan informasi yang sangat cepat dan dalam jumlah yang besar. Sebelum kita dapat memikirkan informasi secara mendalam, media digital sudah menampilkan informasi yang berbeda. Tuntutan adaptif membuat kita hanya sempat mengamati permukaan tanpa mengetahui esensinya. Menghadapi informasi atau peristiwa, kita nyaris tidak memiliki kesempatanmenyesuaikan akal budi dan kenyataan untuk mendapatkan kebenaran. Penyebaran kebohongan dengan dukungan dan internet semakin cepat dengan skala yang besar, bahkan menjangkau audiensi yang tidak direncanakan.

\section{Mengupayakan Kebenaran}

Kemalasan orang untuk mencari informasi yang dibutuhkannya di tengah ledakan informasi, menjadi dasar pemikiran untuk menciptakan sistem algoritma yang memahami perilaku kita dan juga mengenali keluarga, serta rekan-rekan kita. Orang dimanjakan dengan informasi yang sudah dirancang sesuai dengan eksplorasi sistem komputer terhadap kebiasaan kita dan mereka yang berada dalam lingkaran relasi kita. Berkurangnya relasi fisik dan digantikan dengan media digital, sering membuat orang terkejut, karena komputer memiliki pengenalan yang lebih mendalam terhadap orang-orang yang dekat dengan kita. Sistem algoritma mencatat dengan detail tempat yang mereka kunjungi, teman-teman dekat, makanan yang mereka makan, aktivitas yang mereka lakukan, pendapat yang mereka sampaikan, dll. Kondisi ini mengamplifikasi kesenangan kita, dan tanpa disadari membentuk perilaku, opini dan mempolarisasi pemikiran kita.

Permasalahan dari polarisasi ini adalah kita menutup ruang diskusi terhadap kebenarannya yang berseberangan dengan kita atau dikenal sebagai

29 Carrie James, Disconnected: Truth, New Media and The Ethics Gap, Cambridge dan London: MIT Press, 2014, 12. 
'Overton window', ${ }^{30}$ yang memberikan pembatasan pada kerangka pemikiran kita. Jika jendela berpindah, pemandangan kita berganti, tetapi keluasan pemahaman kita tetap sama. Tanpa kesadaran bahwa jendela telah berpindah, kita akan salah arah dengan menganggap telah mengadakan perubahan fundamental, padahal hanya sekedar perubahan perspektif, sementara realitasnya tetap sama. Kita perlu melengkapi pengetahuan kita dengan membuka diri pada sumber berita yang memiliki kredibilitas yang baikdan tidak membiarkan opini berkembang hanya di dalam jaringan (network) dan sepaham dengan kita.

Kebenaran (aletheia/unconcealment) menurut Heidegger adalah ketersingkapan yang mengandung unsur ketersembunyian (unconcealment). Definisi ini menunjukkan bahwa kebenaran merupakan hal yang mengandung misteri. Kebenaran sebagai ketersingkapan kenyataan sebagai adanya, ternyata tidak dapat disaksikan secara sekaligus dan menyeluruh.Karakter manusia yang terbatas mengakibatkan setiap penyingkapan (disclosure) tidak pernah sama sekali terbebas dari perjumpaan dengan tabir (closure) berikutnya yang menutupi realitas. ${ }^{31}$ Penjelasan Heidegger ini menunjukkan bahwa pencarian dan penemuan kebenaran merupakan proses yang berkelanjutan.

Sikap kritis merupakan langkah awal untuk mengupayakan kebenaran. Sikap ini harus diikuti dengan kehendak untuk memperoleh kebenaran faktual objektif dengan mencari sumber informasi yang dapat dipercaya. Kebutuhan inisebenarnya sudah menjadi gerakan masyarakat yang sudah menjadi gerah dengan memburuknya relasi dan komunikasi karena sikap agnostik-indiferen terhadap kebenaran. Gerakan untuk menyediakan fakta kebenaran yang dengan mudah diakses melalui media digital menjadi strategi memerangi hoax dan fake newos dengan cara yang sama dengan penyebarannya.Beberapa situs yang yang tersedia antara lain mediabias, politifact, factcheck atau cek fakta untuk versi Indonesia. Pemerintah juga membuka berbagai situs resmi yang dapat diakses untuk mendapatkan berita yang benar.

Kita masih sangat mengharapkan informasi yang benar. Informasi yang bukan hanya tidak mengandung kesalahan, tetapi juga informatif dan reliabel..$^{32}$ Kredibilitas sumber merupakan acuan, sehingga juga bisa menjadi filter yang membantu untuk memperoleh informasi yang benar. Beberapa kriteria dapat dijadikan panduan, seperti hasil penelitian akademis dari perguruan tinggi, tweeter dari tokoh yang kredibel, informasi dari sumber pertama lebih dapat diandalkan kebenarannya dibandingkan pesan yang

30 Bruce Barlett, The Truth Matters: A Citizen's Guideto Separate Factsfrom Lies and StoppingFake News in Its Track (New York: Ten Speed Press, 2017), 72-74.

31 J. Sudarminta, Epistemologi Dasar: Pengantar Filsafat Pengetahuan (Yogyakarta: Kanisius, 2002), 128- 129.

32 Bernard Williams, Truth and Truth fulness (New Jersey: Princeton University Press, 2002). 759. 
sudah diteruskan berulang. ${ }^{33}$ Meskipun media digital memiliki akurasi yang tinggi, tetapi ada kemungkinan termodifikasi dalam proses meneruskan berita atau informasi. Kreativitas dan inovasi mempunyai peran selain untuk menemukan hal baru dan menerapkannya, tetapi juga dapat menjadi sarana penipuan ketika digunakan untuk menyembunyikan atau mengubah realitas.

Masyarakat kita masih mengharapkan pemikir yang kompeten dan jujur, serta jurnalis yang menulis non fiksi untuk tetap mempertahankan kredibilitasnya meskipun dalam peti mati media yang baru. Kejujuran mengandaikan penghormatan pada kebenaran. ${ }^{34}$ Meskipun kebenaran dalam keseharian berbeda dengan interpretasi narasi historis dan interpretasi psikologi yang rumit, tetapi menggenggam keutamaan-keutamaan untuk mendapatkan kebenaransulit dihidupi, karena memerlukan kehendak untuk menemukan kejujuran, memeluknya dan kesediaan untuk menyatakannya secara partikular pada dirinya. Hanya dengan kejujuran dan kebenaran kita dapat saling percaya, menetapkan tujuan-tujuan bersama dan memperjuangkannya.

\section{Penutup}

Teknologi digital menyediakan jalur baru yang lebih cepat dan kaya untuk membagikan konten dan berhubungan satu dengan yang lain dalam skala yang sangat luas. Karakteristik ini mewajibkan kita untuk memahami bahwa pemikiran yang kita sampaikan, meskipun dalam lingkup terbatas, memiliki potensi untuk tersebar dalam jaringan yang lebih luas dalam web dan berdampak terhadap orang lain. Kita dapat meminimalisir salah interpretasi dalam komunikasi melalui web dan internet.Hal ini dimungkinkan karena proses menyampaikan pemikiran dapat dilakukan dengan memilih dan menyusun kata-kata, merefleksikan dan melakukan suntingan sebelum mengirimkan pesan. Hal ini sering terabaikan ketika kita menggunakan media digital bersamaan dengan melakukan kegiatan lain. Konten yang tidak sempat lagi direfleksikan kebenaran dan kegunaannya dapat tersebar luas. Selain itu, kita juga perlu menyadari bahwa pesan yang kita sampaikan dapat dimodifikasi dan 'dipelintir', sehingga pesan yang diterima berbeda dengan tujuan penulisnya.

Banyak pengguna media digital yang lebih memilih menggunakan teks untuk berkomunikasi, karena menurut mereka tidak terlalu dekat, tidak terlalu jauh, tetapi berjarak. ${ }^{35}$ Orang dapat mengirimkan pesan teks sambil mengerjakannya kegiatan lain (multitasking), karena adanya telepon genggam yang mudah dibawa kemanapun. Akibatnya sering terjadi salah pengertian dan melukai perasaan. ${ }^{36}$ Selain bersifat emosional, menyemangati dan memberi

33 Barlett, The Truth Matters, 13-19.

34 Bernard Williams, Truth and Truth fulness (New Jersey: Princeton University Press, 2002). 39.

35 Ibid, hlm. 15.

36 Sherry Turkle, Alone Together, 167-168. 
dukungan, kita juga dapat menghadapi masalah atau harus menjelaskan hal yang sederhana, yang sudah berubah menjadi situasi yang rumit.

Komunikasi termediasi dan berjarak memungkinkan kita untuk setiap saat mematikan daya dan menarik diri. ${ }^{37}$ Kondisi ini memberi ruang untuk anonimitas yang dikonstruksikan, sehingga kita dapat tampil sebagai pribadi yang diinginkan. ${ }^{38}$ Kondisi ini menimbulkan celah empiris danetis yang harus dijembatani melalui relasi yang aman dengan kualitas yang baik.Kita perlu memilih komunitas yang benar dan membatasi keterlibatan dalam 'keterasingan' yang rentan. Setiap individu mempunyai tanggung jawab untuk menyeimbangkan kehidupan online dan offline-nya. Kita perlu menyisihkan waktu untuk mendesain hidup, mempertahankan keamanan, reputasi dan integritas. Pengguna media digital perlu untuk tetap berkomitmen pada kebenaran akan mendukung untuk menciptakan rekam jejak digital sebagai pengguna media digital yang baik. Realitas digital merupakan realitas yang bertambah, karena berbeda dengan manusia yang dapat melupakan dan memaafkan, maka media digital hanya bisa menyimpan semua data tanpa memilahnya. Semakin sering kita menggunakan media digital, maka data kita yang tersimpan dalam media digital semakin rinci. ${ }^{39}$ Pengalaman Covid-19 yang memaksa kita lebih humanis dengan memperbaiki kembali relasi-relasi dengan keluarga dan komunitas yang selama ini terkooptasi kesibukan kita. Kondisi ini seharusnya menyadarkan kita bahwa kemanusiaan kita dapat diperkaya oleh relasi-relasi yang menggerakkan kita pada kebersamaan dan solidaritas, dan bukan melalui mekanisme transaksional.

Kebenaran merupakan kualitas manusia yang merupakan konstruksi mental, dan bukan kondisi fisik. Heidegger menganggap teknologi sebagai salah satu cara atau model pengungkapan yang dapat digunakan sebagai sarana untuk menjadikan dunia sebagai tempat pengungkapan dan keterbukaan pada kebenaran (aletheia). Media digital dapat menjadi sarana untuk mempererat hubungan keluarga, membangun relasi dengan sesama dan dunia.Melalui komunitas yang berlandaskan kebenaran dan kejujuran, media digital dapat mendukung pengembangan dialog yang tulus dan solidaritas berdasarkan kebenaran. Sebaliknya kebohongan publik merupakan patologi sosial yang mengindikasikan lunturnya kepercayaan antar individu, serta redupnya ikatan sosial dalam kehidupan komunitas. Kita perlu menyadari konsekuensi redupnya ikatan sosial dalam suatu komunitas yang

37 James, Disconnected, 13-14.

38 Op. cit. hlm. 158.

39 Data yang dimaksudkan di sini adalah data di luar unggahan kita di sosial media. Tetapi aktivitas harian kita yang gadget. Komputer akan mencatat ke mana kita pergi, barang apa yang kita beli, makanan yang kita pesan, siapa yang sering kita hubungi, bahkan aktivitasaktivitas privat yang tidak kita harapkan untuk diketahui orang lain. Data-data ini dapat digunakan untuk memprediksi kegiatan kita dan juga menjadi komoditi yang diperdagangkan untuk kepentingan komersial. 
berarti memberi ruang pada dominasi kepentingan individu atau kelompok yang cenderung menangnya sendiri. Kita dituntut untuk memilah dan memilih sumber-sumber informasi ataupun sosok yang memiliki pengalaman dan tidak memiliki alasan untuk berkata tidak jujur. Era post-truthmenuntut konsistensi, keberanian dan disiplin untuk mempertahankan kebenaran dari arus informasi yang korosif.

\section{Kepustakaan}

Barlett, Bruce. The Truth Matters: A Citizen's Guide to Separate Facts from Lies and Stopping Fake Nerws in Its Track, New York: Ten Speed Press, 2017.

Cameron, dkk. Deception in the Digital Aging: Exploiting and Defending Human Target Through Computer Mediated Communication, London: Academic Press, 2017.

Campbell, Richard. dkk. Media \& Culture: Mass Communication in Digital Era, New York: St. Martin's, 2014.

Davidowitz, Seth Stephens. Everybody Lies: Big Data, New Data and What Internet Can Tell Us About We Really Are, Sydney: Harper Collins Publisher (Australia) Pty, Ltd., 2017.

Floridi, Luciano. The On life Manifesto: Being Human in Hyper connected Era, London: Springer Open, 2011.

Heidegger, Martin. Being and Time, terjemahan Joan Stambaugh. New York: State Universityof New York, 1996.

Heidegger, Martin. The Question Concerning Technology and Other Essays, terjemahan William Lovitt. London: Garland Publishing, 1977.

J.A. Ward, Stephen. Ethics and the Media, New York: Cambridge UniversityPress, 2011.

James, Carrie. Disconnected: Truth, New Media and The Ethics Gap, Cambridge dan London: MIT Press, 2014.

James, Carrie, dkk. Young People, Ethicsand New Digital Media: A Synthesis from the Good Play Project, Cambridge dan London: The MIT Press, 2009.

Keyes, Ralph. The Post Truth Era: Dishonesty and Deception in Contemporary Life, New York: St Moritz Press, 2004.

McCraw, David E. Truth in our Times, Inside the Fight for Press Freedom in the Age of Alternative Facts, New York: All PointsBook, 2019.

Nietzche, Friedrich. Philosophy and Truth: Selection from Nietzche Notebook of Early 1870, Editor dan terjemahan Daniel Breazeale. New Jersey: Humanity Press. Bab IV, hlm. 79 - 91.

Smith, Philip dan Riley, Alexander. Cultural Theory and Introduction, Oxford: Blackwell Publishing, 2009. 
Sudarminta, J. Epistemologi Dasar: Pengantar Filsafat Pengetahuan, Yogyakarta: Kanisius, 2002.

Sudarminta, J. Setia Pada Kebenaran: Sumbangan Filsafat sebagai Ilmu Kritis, Pidato Pengukuhan Guru Besar Ilmu Filsafat, Jakarta: STF Driyarkara, 2007.

Sumpter, David. Out numbered: From Facebook and Google Fake News and Filter Bubbles - That Algorithms that Control Our Lives, London: Bloomberg Sigma, 2018.

Turkle, Sherry. Alone Together: Why We Expect More from Technology and Less from Each Other, New York: Basic Book, 2011.

Wheeler, Tom. Photo truth or Photofiction?: Ethicsand Media Imaginery in the Digital Age, New Jersey: Lawrence Erlbaum Associates Publishers, 2002.

Williams, Bernard. Truth and Truth fulness, New Jersey: Princeton University Press, 2002.

Kelly, James D. (Pengantar), Tom Wheeler, Phototruthor Photofiction?: Ethicsand Media Imaginery in the Digital Age, New Jersey: Lawrence Erlbaum Associates Publishers, 2002.

\section{Sumber lain:}

Pesan Bapa Suci Paus Fransiscus untuk Hari Komunikasi Sedunia Ke-53, diunduh 7 Mei 2019. wwww.mirifica.net/2019/02/15/pesan-paus-untuk-harikomunikasi-sedunia-ke-53. 